
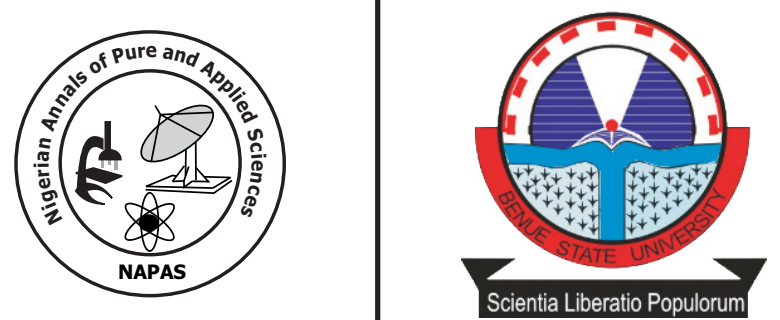

\title{
Measurement of Magnetic Susceptibility on Some Rock Samples in Parts of Kuje Area, Abuja-Nigeria
}

\author{
Abdulsalam, N.N. ${ }^{1}$ and Ologe, O. $^{2}$ \\ ${ }^{1}$ Department of Physics, \\ University of Abuja, Nigeria \\ ${ }^{2}$ Department of Applied Geophysics, \\ Federal University Birnin Kebbi, Nigeria
}

\begin{abstract}
Magnetic Susceptibility values are important in interpreting regional magnetic anomalies and in crustal modeling. In this study, Magnetic Susceptibility has been measured on rock samples from the sedimentary succession of Kuje Area in FCT. Variation of susceptibility for the different samples has been analyzed and confirm in the study. According to the measured susceptibility values based on the selected samples, the minimum susceptibility value for sedimentary rocks was found to be 0 which was the minimum value obtained for Dolomite and the maximum susceptibility value for sedimentary rocks was found to be $1480 \mathrm{cgs}$ which was the maximum value obtained for shales. For metamorphic rock, the minimum susceptibility value was found to be $25 \mathrm{cgs}$ which was the minimum value obtained for schists and its maximum susceptibility value was found to be $3,000 \mathrm{cgs}$ which was the maximum value obtained for slate. Finally, the minimum susceptibility value for igneous rocks was found to be $20 \mathrm{cgs}$ which was the minimum value obtained for rhyolite and its maximum susceptibility value was $14500 \mathrm{cgs}$ which was the maximum value obtained for basalts
\end{abstract}

Key words: Magnetic Susceptibility, magnetic anomalies, Anisotropy, sedimentary rocksand remanence. 


\section{Introduction}

The Federal Capital Territory is dominated by a high grade metamorphic and sedimentary succession, compaction in the deep sedimentary basin resulting in a decrease in both Acoustic impedance contrast and the signal to noise ratio because of densities, close up to basement rocks are leading to large uncertainties estimating the top-basement in both seismic and gravity (Barrere 2009). The Magnetization contrast between Sedimentary and basement rock is usually high and therefore an interpretation of the magnetic field is generally effective in basement/rock studies (Dallmann, 2010). Due to the ambiguity in magnetic field interpretation, constraining data is needed.

Sedimentary magnetic studies have been done earlier of the quartz-bearing stones of the Gwagwalada Area which revealed low Susceptibility. However, the OSRAM project (Origin of Sediment Related Aeromagnetic) documented that part of the off stone Mesozoic and Cenozoic Sedimentary succession are Magnetic (Carmichael, et al 2002) and that finer clastic sediment have higher susceptibility than the coarse grained sand stone (Olesen et al. 2010, Agdestin, 1980, Anderson, 1990). This also is compatible with the result from magnetic susceptibility study of kuje Area. Carried out during the field work

This work intends to achieve the following:

- Provide primary information about magnetic susceptibility of some rock in the study area.

- $\quad$ Present information on data acquisition on magnetic susceptibility test from the case study

- To examine variation in magnetic susceptibility between the samples and to investigate the mineral-logical source of the susceptibility in rock studied.

\section{Geological Settings of the Study Area}

The FCT is almost predominantly underlain by high-grade metamorphic and igneous rocks of Precambrian age. Generally trending NNE$\mathrm{SSW}$, these rocks consist of gneiss, migmatites and granites (kayoed and olaogun, 2010). A schist belt outcrops along the eastern margin of the area. The belt broadens southwards and attains a maximum development to the southeastern sector of the area where the topography is rugged and the relief is high. In general, the rocks are highly sheared (Kayoed Olaogun, 2010).

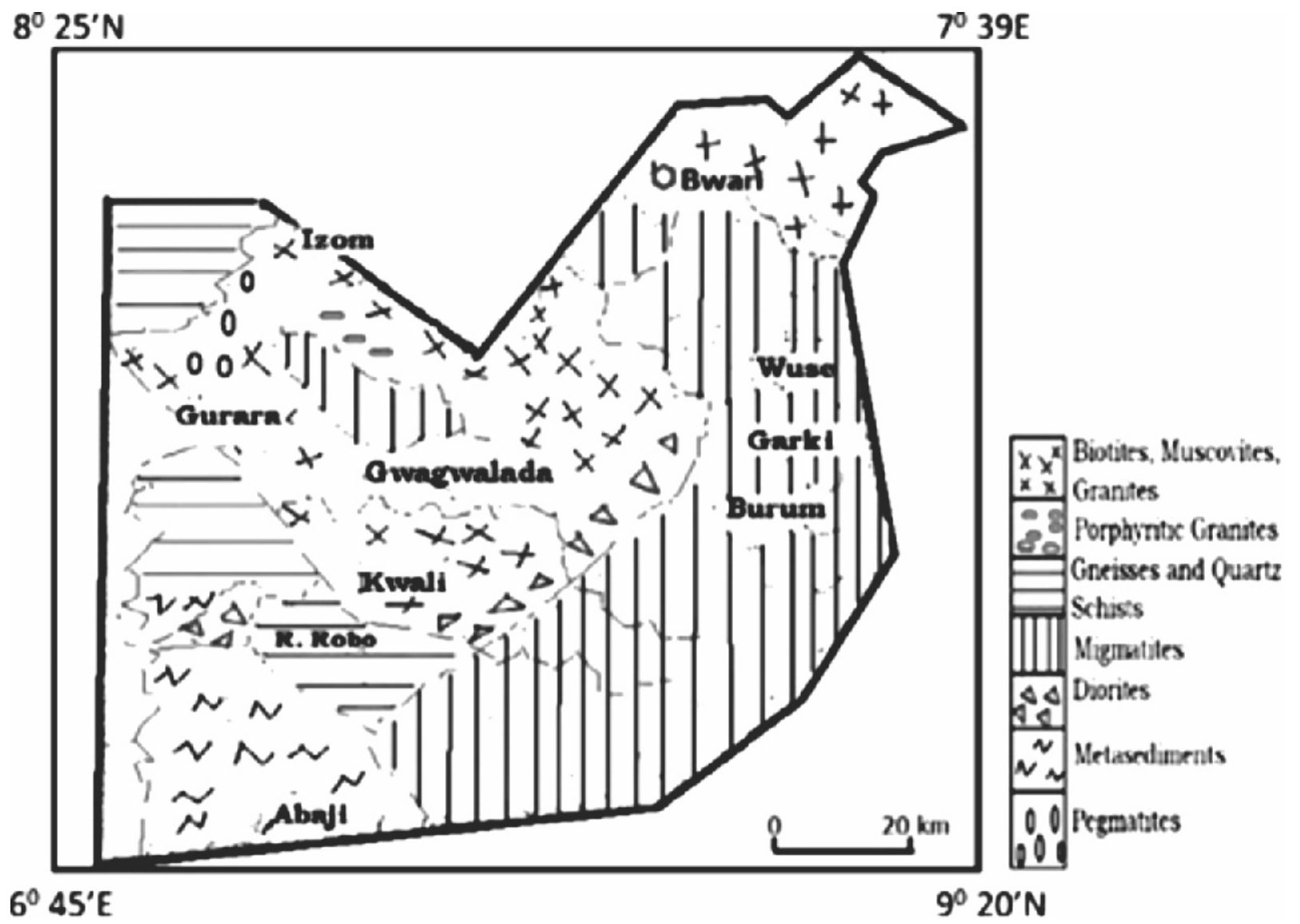

Fig. 1: Geological map of The Federal Capital Territory 
The rocks of the area can be divided into five major groups, as follows:

- Metamorphosed Supracrustal (Exogenetic) Rocks: Mica schist, marble, amphibolites and amphibole schist, finemedium grained gnesis.

- Magmatic Complex: Migmatite gneiss, granite gneiss, porphyroblastic granite gneiss, leucocratic granite gneiss, intrusive granite, coarse grained granite.

- Minor Intrusions: rhyolites, quartz feldspar porphyry, dacatitea and anddesites, dolerites and basalts.

- Other Formations: quartizite, pegmatite, quartz vein.

\section{Materials and Methods \\ Sample Acquisition}

A total of 10 samples have been collected during field work in both sedimentary and metamorphic succession from exposure in Gwagwalada. The samples have been collected throughout the geological surface formation in respective area in Kuje, FCT Abuja. The sampling areas include chukuku (A), kiyi (B) and chibiri (C), Kuje area Abuja, Nigeria. The collected rock samples were then labeled respectively.

\section{Analysis of Rock Samples by Magnetometer}

The rock samples were analyzed using a magnetometer. Each sample was measured one after the other and the measurement were done at the National Geoscience Research Laboratory in Kaduna, Nigeria. In order to fulfill the requirement to be stored in the National Geophysical Database, the samples must exceed 50g and contain UTM co-ordinate (Olesen et al. 1993). The practical work include compiling background data and preparation of sample list, sample identification and sample preparation, Identification of UTM co-ordinate from location map, laboratory measurement of density, magnetic susceptibility and remanance were carried out.

\section{The Measuring Weight}

After checking that the weights reads zero, the sample is then placed on top of the weight for dry-weight measurement saturated with water. The sample is then put in the water container under the wet weight measurement.

\section{Volume Susceptibility}

Measurement where performed using a frequency oscillator and a frequency counter, the susceptibility of a sample is calculated from the frequency difference between empty coil and coil with inserted sample. The best suitable pick-up coil $(92,64$ or $103 \mathrm{~mm}$ in diameter) is selected dependent on the size of the sample. The period of the coil ratimer than the frequency is measured. A measurement of empty coil is done after pick-up coil is selected.

\section{Anisotropy of Magnetic Susceptibility (AMS)}

Since independent components must be determined to define the susceptibility ellipsoid. AMS measure the shape, preferred crystagraphic orientation, preferred particle orientation or preferred distribution of ferromagnetic and paramagnetic grains. Analysis and interpretation of AMS data requires a detailed characterization of the sources of AMS. Studies

\section{Results and Discussion}

The magnetic susceptibilities of some common rock samples in Gwagwalada area are presented in the table below.

Table1: Magnetic Susceptibility of Some Rocks

\begin{tabular}{lll}
\hline ROCK TYPES & \multicolumn{2}{l}{ SUSCEPTIBILITY X $\mathbf{1 0}^{6} \mathbf{c g s}$ UNIT } \\
& RANGE & AVERAGE \\
\hline SEDIMENTARY & $0-75$ & 10 \\
Dolomite & $2-280$ & 25 \\
Limestone & $0-1660$ & 30 \\
Sandstone & $5-1480$ & 50 \\
Shales & & \\
METAMORPHIC & $25-240$ & 120 \\
Schist & $10-2000$ & 130 \\
Gneiss & $0-3000$ & 500 \\
Slate & & \\
IGNEOUS & $20-3000$ & 1400 \\
Rhyolite & $80-7200$ & 6000 \\
Gabro & $20-14500$ & 6000 \\
Basalts & & \\
\hline
\end{tabular}


For Dolomite which is a sedimentary rock, the minimum value obtained was found to be 0 and the maximum value obtained was found to be 75 which make its range of value to be from 0-75. Also the range of value has been shown for limestone, sandstone, shales respectively, and high susceptibility value.Magnetometer was used to examine the susceptibilities of selected samples, the results revealed noticeable variation among the samples.
Although the susceptibility was low for sedimentary rocks and there was a clear trend that the metamorphic and the igneous rocks have the highest susceptibility. Siderite and pyrite was found to be the mineralogical source of those with high susceptibility and the amount of siderite and pyrite that are present in each of the igneous and sedimentary rock also varies. Consider the Conventional table below.

Table 2: Conventional Table of Magnetic Susceptibility (Telford, et al, 1990)

\begin{tabular}{llll}
\hline Rock Type & \multicolumn{2}{l}{ Susceptibility X $10^{6}$ cgs units } & Average \\
\hline Sedimentary rocks & Low & High & 8 \\
Dolomite & 0 & 75 & 23 \\
Limestone & 2 & 280 & 32 \\
Sand stone & 0 & 1665 & 52 \\
Shales & 5 & 1478 & 349 \\
Basement Rocks & & & 647 \\
Metamorphic & 0 & 5874 & 2596 \\
Acid Igneous & 3 & 6527 & \\
Basic Igneous & 44 & 3711 &
\end{tabular}

Generally, the range of values of magnetic susceptibility is low in sedimentary rocks compare to igneous and metamorphic rocks. Comparing this with the measured values in Table 1, the range of values for the susceptibilities is close.

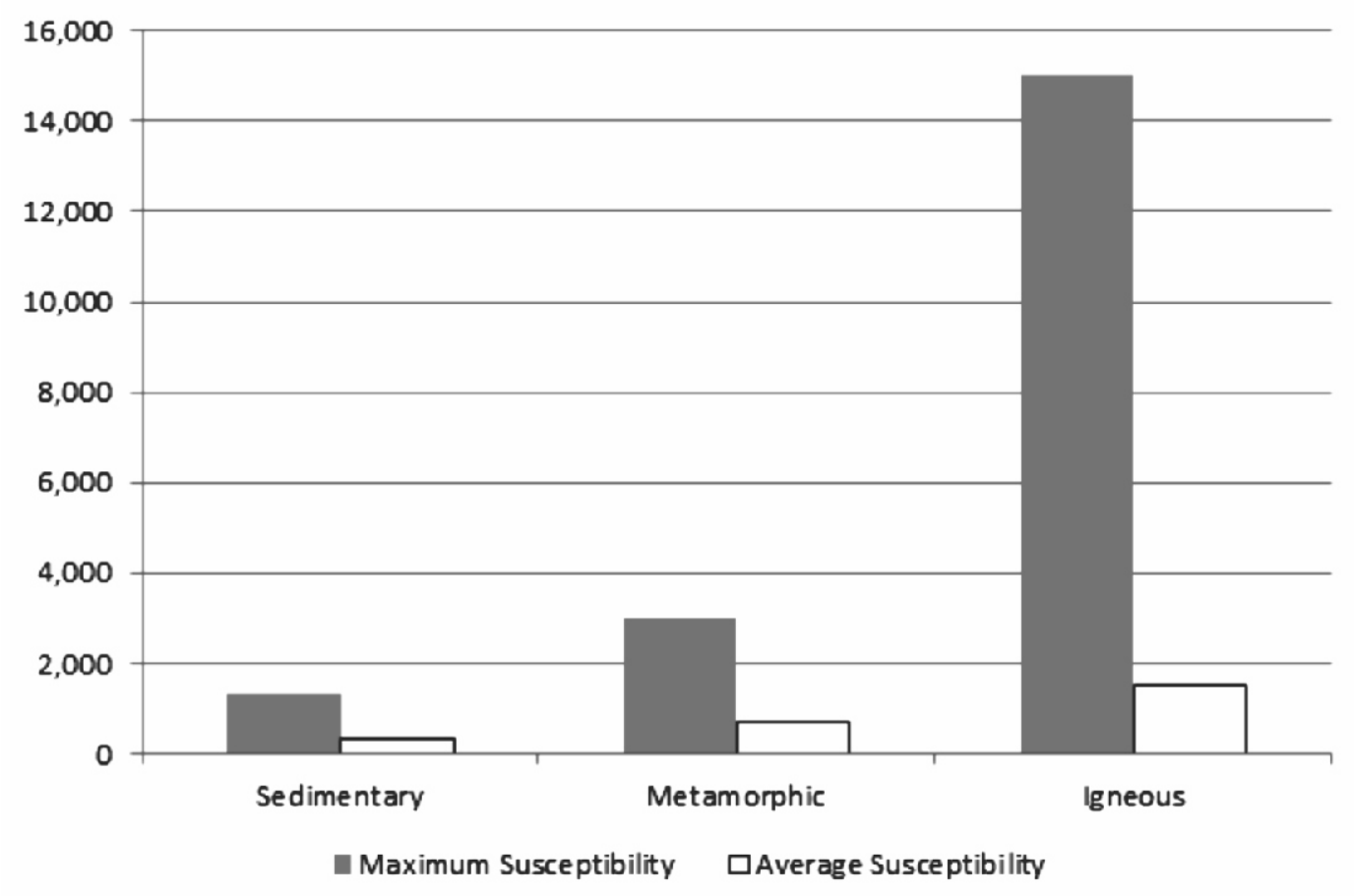

Figure 2: showing Ranges of Each Rock Types

\section{Mineralogical Impact on Rocks}

Mineralogical comparisons of experimental results investigating the biological impacts on rock transport processes. This examines the influence of microbes on fluid transport in sedimentary and igneous rock environments (Houslow et al 1995). It particularly focuses on granodiorite rock and mudstone that were utilized during laboratory based column experiment. The results showed that bio films form on both rock types in low nutrients conditions. Cryogenic scanning electron microscopy showed that the morphology of biofilament varied from faliamentous meshwork to clusters of rod-like cells (fracture surface in mudstone) $x$-ray diffraction analysis on the time fractions ( $<$ stem) 
revealed the formation of secondary clay mineral phases (Hauser, 1986)within the crushed granodiorite rock substrate only. The formation of secondary clay minerals appears to be enhanced when bacteria are presents. All experiments showed biofilm formation, bacterial pore throat and secondary clay mineral formation. These observations illustrate the importance of bacteria on rock transport properties which will impact on the containment and migration of containments.

The problem of stability over time should be considered for slopes excavated in soft rocks, in case they are not protected against weathering processes. In addition to disintegration of materials $\mathrm{n}$ slope surface, the weathering also results in swear strength reduction in the interior of the slope. Principal processing in association with weathering and discussed with examples of the slope stability.

Surface degradation processes and local landslide occur frequently on slopes excavated in soft rocks. As a result, safety of facilities at the bottom of these slopes is threatened and the cost of maintenance and/or supporting is usually significantly high. At the same time, the stability facilities located at the top of such slopes is also submitted to increasing risk. The excavation work in the geomaterial (mostly clayey rocks such as marls, siltstone, mudstone, shales) can be performed only with use of heavy machinery or explosive as well as in other types of rocks. However, in a relatively short time after excavation, the excavated slope surface and the rock inside. These processes can be observed on many natural slopes and on cuts excavated in flysch formations in the region of Dalmatia, Croatia which were formed in the Eocene epoch and usually consisted of marl as the main soft rock component.

Information about marl strength at all phases of slope exploitation is of utmost importance for any stability analysis of cuts data for analysis of cuts and slope in this geomaterial. To provide data for analyzing the strength deterioration of rocks, there should be a possibility to test degraded material weathering processes fragmented marl sample into smaller pieces, thus the fragmented sample is very difficult to be operated with and to be installed into a testing device. For the solution of this problem, addition to the standard test procedure was used. Addition refer to the standard procedure of a direct swear test method (ISRM suggested method for determining swear strength in 1974) enabling the tests of deteriorated sample. The main scope of the presented study is to identify the mineralogical impact on rocks, some basic engineering observations or precious experiences on known examples of observers slope in this material and propose solution associated with those observations for future project and studies. Also it is important to emphasis the necessity of proper engineering solutions that prevent the developments of the weathering process which can lower the potential of slope instability and the maintenance cost.

An example of surface deterioration is induced by weathering of a natural slope situated on the Adriatic highway in the municipality. Example of the mineralogical impact on rocks can be found on many locations in those geomaterials. For instance such situations are quite frequently reported in the vicinity of split when excavation are made in rock mass

\section{Remanence}

The remanence measurements were done using a fixed schonstedt fluxgate magnetometer, positioned within a two-layered u-metal shield cylinder open in both ends. The fluxgate probe is monitored from the schonstedt digital magnetometer and an analog signal is transferred to a digital voltammeter and then to a PC.

After the background field value is measured, the sample is inserted close to the probe $(10 \mathrm{~cm}$ from Centre of samples to the probe) inside a sample holder and measured again. The remanence of the sample is then determined by varying sample position according to Cartesian design and measuring corresponding field values.

The sample positions according to Cartesian design:

$\begin{array}{ll}1 & \text { sample remanence in }+x \text { direction }\left(\mathrm{x}_{1}\right) \\ 2 & \text { sample remanence in - } \mathrm{x} \text { direction }\left(\mathrm{x}_{2}\right) \\ 3 & \text { sample remanence in }+\mathrm{y} \text { direction }\left(\mathrm{y}_{1}\right) \\ 4 & \text { sample remanence in -y direction }\left(\mathrm{y}_{2}\right) \\ 5 & \text { sample remanence in }+\mathrm{z} \text { direction }\left(\mathrm{z}_{1}\right) \\ 6 & \text { sample remanence in - } \mathrm{z} \text { direction }\left(\mathrm{z}_{2}\right)\end{array}$

The total remanence $(\mathrm{m})$ of the sample can be determined by the formula.

$\mathrm{M}=\left(\mathrm{xm}^{2}+\mathrm{yn}^{2}+\mathrm{zm}^{2}\right)^{1 / 2}(\mathrm{ma} / \mathrm{m})$. Where $\mathrm{X}_{\mathrm{m}}=\left(\mathrm{x}_{1}\right.$ $\left.\mathrm{x}_{2} / 2\right), \mathrm{Y}_{\mathrm{m}}=\left(\mathrm{y}_{1-} \mathrm{y}_{2} / 2\right)$,

$\mathrm{Z}_{\mathrm{m}}=\left(\mathrm{z}_{1}-\mathrm{Z}_{2} / 2\right)$

The schonstedt fluxgate magnetometer is calibrated against a molspin spinner magnetometer capable of measuring NRM intensities down to approximately $0.1-0.2$ $\mathrm{mA} / \mathrm{m}$, approximately 1000 times more sensitive than the schonstedt fluxgate magnetometer (Carmishapl, 1982). The sensitivity depends on the volume of the sample, approximately $50-100$ $\mathrm{mA} / \mathrm{m}$ for $900 \mathrm{~cm}^{3}$ samples. 


\section{Density}

Volume and density can be derived from measuring dry and wet weight of a sample according to time Archimede's principle. However, time samples must be saturated in water at least 12 hours before measurements. A precise $4200 \mathrm{c}$ gcs weight connected to a PC is used at the laboratory with a resolution power of 0.1 gram.

Volume and density are calculated from the following formulas.

$\mathrm{V}=\mathrm{W}_{\text {dry }}-\mathrm{W}_{\text {wet }}\left(\mathrm{cm}^{3}\right)$,

Where $\mathrm{V}=$ volume $\left(\mathrm{cm}^{3}\right)$

$\mathrm{W}_{\text {dry }}=$ dry weight $\left(\mathrm{cm} / \mathrm{s}^{2}\right)$

$\mathrm{W}_{\text {wet }}=$ wet weight $\left(\mathrm{cm} / \mathrm{s}^{2}\right)$

$\mathrm{M}=\operatorname{mass}(\mathrm{w})$

$\mathrm{P}=\operatorname{density}\left(\mathrm{kg} / \mathrm{m}^{3}\right)$

\section{Conclusion}

Noticeable variations of magnetic susceptibilities were discovered among the rock samples. The gabro, Rhyolite generally had the highest susceptibilities while the dolomite, sandstone and limestone had the lowest susceptibilities value. Siderite in addition to pyrite was found to be the mineralogical source of the relative high susceptibilities. No other re-bearing heavy minerals like magnetite were found in scanning electron microscope (sem).Calculation of Q-value revealed high value for the lithologies in addition to the geological surface formation which is an indicator that remanence is important for magnetic anomaly interpretation. The measurement of magnetic susceptibilities of rocks is therefore recommended in the area of specialization like geo-physics, geology e.t.c. for the purpose of proper interpretation of magnetic anomaly.

\section{References}

Agdestin, T. (1980). EnStratigratsk, sedimentary, Svalbard, unpublished thesis, University of Oslo, Norway.

Anderson, J.G. (1990). Uber die strtgraphie. Bulleting of the geological Institution of the University of Uppsala 7, 243-280

Barrere, C. (2009). Integrated geophysical modeling and tectonic evolution of the western Barentssea. Phd thesis, NTNU, Norway.

Carmishapl, R.S., (1982). Magnetic properties of minerals and rocks: CRC handbook of physical properties of rocks, vol. $2 \mathrm{ch} .2$, ed.

Carmichael, R.S., Dallai, G.E., and Wilkinson, L., (2002). An analytic approximation to the distribution Lillipfor's test statistics for normality density of rocks and minerals: CRL Handbook of physical properties of rocks vol.3

Dallmann, W.K. (ed). (2010). Lithostratigraphic lexicon of Svalbard. Review and Recommendation for nomenclature use.Upper Palapozoic to Quaternary bedrock.NorskPolarinstitute, tromso, g18p.

Houslow, M.W.; maher, B.A.; and thistipwood, L. (1995). magnetic mineralogy of sandstone from the lunde formation. Geological society special publication $98,119-147$.

Hauser, T.R. (1986). A handbook on magnetic susceptibility of rocks.

Kayode O., (2010). A handbook on magnetic susceptibility of rocks.

Torsvik, T.H. and Olesen, O. (2010). Petrophysical and paleomagnetism initial report of the norweigan geological survey laboratory. 